\title{
IMPROVEMENT OF FRACTURE NETWORK MODELING IN FRACTURED RESERVOIRS USING CONDITIONING AND GEOSTATISTICAL METHOD
}

\author{
Seyyedeh Ellieh Moafi Madani ${ }^{\text {a }}$ H. Hassani ${ }^{a^{*}}$, B. Tokhmechi ${ }^{\text {b }}$ \\ a Department of Mining Engineering, Amirkabir University of Technology, Tehran, Iran, e-mails: as_madani @ aut.ac.ir, \\ * hhassani@aut.ac.ir, Tells: 09124572738 / 09121758210 \\ ${ }^{\mathrm{b}}$ School of Mining, Petroleum and Geophysic, Engineering, Shahrood University of Technology, Shahrood, Iran, e-mail: \\ tokhmechi@ut.ac.ir, Tell: 09121873486
}

Received: 22.08.2020 / Accepted: 01.09.2020/ Revised: 10.10.2020 / Available online: 15.12.020

DOI: 10.2478/jaes-2020-0022

KEY WORDS: fracture modelling, conditioning, petroleum, geostatistic.

\begin{abstract}
:
The fracture network in hydrocarbon reservoirs plays a major role in reservoir fluid transfer to production wells. Modeling of fracture in fractured reservoir is often done randomly. Modelling is based on image logs and core information. Because the information is available in a small number of wells, the model is not reliable and this problem makes it impossible to predict the correct flow rate and the amount of wells produced. In this study, an algorithm based on primary and secondary data for fracture network modelling in one of the southwest fields of Iran has been presented. The initial data include aperture fracture and fracture density, and secondary data includes petrophysical data, i.e. electrical resistance and resistance logs used to scale-up characteristics of fracture in wells. In this study, we tried to increase the accuracy of modelling by using modelling conditionality on existing and constructed data. Gaussian conditional simulation produces a set of realizations on which non-linear statistics can be readily available. In this way, information was entered into the model in areas where fracture was predicted to exist. Using the turning bands co-simulation method in geostatistic, the fracture characteristics were simulated in wells that were not available. Using the results of the 3D model, the fracture of the reservoir was re-constructed. The results showed that the modelling performed in this study has been able to increase the fracture prediction accuracy and their properties in fracture density by about $9 \%$ and in the fracture opening by about $5 \%$.
\end{abstract}

\section{INTRODUCTION}

Significant percentages of the world's hydrocarbon reserves are located in natural fractured reservoirs, so fractured reservoir modelling is very important. The presence of natural fractures in fractured reservoirs creates complicated paths for flow of fluid that affects reservoir properties, production operations, drilling, and overall recovery (Kuchuk and et al., 2014).

Therefore, the correct recognition of the fracture network and its distribution, in the face of fragile underground resources, helps to optimize drilling, production and exploitation.

Seismic, petrophysical logs, well test, mud loss data, cores and image logs analysis are some direct and indirect methods for determining the fracture in the reservoirs (Tingay and et al., 2008).

Despite the introduction of different models and approaches in the study of the network of fractures in fractured reservoirs, there are still many challenges in this regard. In order to solve these challenges, there are different methods for expanding the nature of the fractured reservoirs, which are divided into three major categories: the equilibrium continuous model, the discrete model and the integration models.

Discrete fracture network (DFN) is a random representation of a natural fracture network. The fracture network is produced by statistical information derived from the field data. In the DFN model, a set of unique fractures is constructed based on randomized descriptions of the properties of fractures such as fracture severity, orientation and size. The technique was created in the 1980s (Long and et al., 1982; Smith \& Schwartz, 1984; Endo and et al., 1984; Robinson, 1984; Dershowtz \& Einstein, 1987; Andersson \& Dverstop, 1987).

DFN is usually calculated based on the statistical parameters calculated by the analysis of natural fracture networks. Problems related to the identification of fracture features such as slope, opening, filling, etc., were resolved after the arrival of image logs in the mid-1980s (Serra, 1989; Schlumberger, 2003).

\footnotetext{
* Corresponding author: Hassani H., Associate Professor, Department of Mining Engineering, Amirkabir University of Technology,
}

Tehran, Iran, e-mail: hhassani@ aut.ac.ir, Tell: 09121758210. 
Image log have high resolution and allow identification of small scale variation But cannot completely solve the problem of detecting fractures because it's found in less than $10 \%$ of all wells (Eskandari, 2008).

So far, many studies have been conducted to improve the accuracy of fracture modelling. Using well data and matching these data with hydraulic fractures properties to improve the fracture model of the reservoir (Hugo and et al., 2004; Srivastava, 2013), examining the relationship between petrophysical logs and image logs (Aghli and et al., 2016) are examples of studies in this regard.

In this study, petrophysical logs have also been attempted to simulate fractures in wells that do not have an image log with the highest possible accuracy. For this reason, the relationship between image logs and petrophysical logs was studied in existing wells based on geostatistical methods. In the geostatistics, we try to analyze and model a region variable in space. The advantage of geostatistics is to calculate the amount of uncertainty in addition to the estimated value.

Geostatistical modelling of oil reservoirs is used in a variety of reservoirs and for various variables (Isaaks \& Srivastava, 1989; Goovaerts, 1997; Deutsch \& Journel, 1998; Wackernagel, 2003; Chiles \& Delfiner, 2009; Pyrcz \& Deutsch, 2014; Maleki \& Madani, 2016). The main reasons for using geostatistical methods for reservoir modelling are the increasing amounts of data at various scales, such as cores, plugs, wells and seismic data for modelling. Geostatistical techniques provide an unambiguous, repeatable, and numerical approach to modelling the reservoir that can also integrate data at different scales. In addition, these methods can provide other characteristics, such as expert opinion (Pyrcz and Deutsch 2014).

In this study, we attempt to model fractured reservoirs with a geostatistical approach. According to Nelson's (Nelson, 2001) definition, a reservoir fracture is a visible macroscopic plate discontinuity that occurs as a result of deformation or physical diagnosis (Nelson, 2001).

Fractures usually occur in the upper crust of the earth; similarly, oil reservoir rocks also have fractures (Narr and et al., 2006).

Reliable estimates are not available on how much of the world's oil is stored in fractured reservoir. However, some estimates suggest it is about 60\%) Beydoun, 1998; Waldren \& Corrigan, 1985).

In fractured reservoir there is a need to describe the fractures. Fracture description requires a range of data to obtain size, orientation, porosity, opening, intensity, or density and permeability (Sahimi, 2011).

Directly related fracture measurements are made only in the wells, and predictions between the wells are difficult due to the complexity (Mäkel, 2007).

According to the above, it is necessary to have an accurate algorithm for fracture network modelling.

Truncated Gaussian simulation and truncated pluri-Gaussian simulation are two methods for simulating the facies. In applying these methods, a good sequence of facies is required, which is a very difficult task. On the other hand, in the truncated pluri-Gaussian simulation, we need to define two or more Gaussian random fields (Chiles \& Delfiner, 2009).

Another method for simulating the facies of the earth is the multiple point geo-statistics. This method has been proposed as a substitute for previous methods. In this method, an educational image is used instead of a variogram to estimate the conditional probabilities at the points of interest for simulation (Journel \& Zhang, 2006).

The multivariate method has the advantage that the modelling is closer to reality. However, there are difficulties in conditional data on dense data wells. There is also the issue of how to obtain and select an educational image (Lyster, 2009).

Geostatistical methods such as kriging and sequential Gaussian simulation can be used to simulate fracture properties. Some researchers have used the correlation between reservoir properties to improve their modelling (Bourbiaux and et al., 2002; Gauthier and et al., 2000). For example, if the porosity of the rock is correlated with the fracture severity, then the fracture model can be used to model the fracture severity limitation Mackel (2007) investigated the probability of the correlation between the layering curvature and the anisotropy in the seismic with the parameters of the fracture network, such as intensity and direction.

Since coring is from a well with a high cost, in some fractured reservoir, there are a few wells with core fracture measurements. Image logs come at a lower cost; however, they are still in the small number of wells. In these cases, very little data is available to examine the correlation between the fracture severity and other data obtained from the well. Coefficients of correlation show large dependencies on outside values (Isaaks \& Srivastava, 1989; Kim \& Fessler, 2004; Shevlyakov, 1997) and the amount of uncertainty can be very high when the number of data is low (Kalkomey, 1997).

A discreet fracture network is a model of fractures in the rock. The main purpose of its creation is to study the relationship created and the hydraulic potential created by the fracture network inside the reservoir and its effect on production (Bourbiaux and et al., 2005; Mäkel, 2007). Since lithology plays an important role in the development of natural fractures, the developed lithology model can already be used to restrict the fracture network model (Cacas and et al., 2001).

The Baecher model (Baecher and et al., 1977; Baecher, 1983) was one of the first models used to produce a fracture network. Under the proposed model, fracture centers are obtained randomly from the Poisson distribution. Fractures are also created in the form of discs with specified orientation and radius. The improved Baecher model (Dershowitz \& Einstein, 1988) presented the Baecher model by specifying the ranges for fracture termination and fracture in its entirety. A number of other researchers have presented data from a fracture network that follows a fractal pattern. Hence, models have been developed to create fracture network fractal (Mandelbrot, 1983; Clemo, 1994; Stach and et al., 2001; La Pointe, 1988; Ghosh \& Daemen, 1993). 
Some other research focused on fracture growth since its inception Renshaw and Pollard (1994) developed the fracture network with geomechanical concepts. Srivastava's (2006) method is an imitation of the high-level method, in that the fractures extend at their tip, but instead of using geomechanical methods, statistical rules are obtained.

Generally, statistical models in the reservoir have a wide application and, in particular, in fractured reservoirs, are often based on the correlation coefficients obtained between primary and secondary values. However, although applying correlation coefficients has a long history in the modelling of parameters related to all reservoirs such as facies, porosity and permeability, the modelling of the parameters related to fracture is much less used. Therefore, in this study, we tried to find the relationships between the fracture characteristics and the parameters obtained from the logs and to use for fracture network modelling. As mentioned, it is expected that the use of secondary variables, i.e. parameters derived from well logging, including electrical resistance and porosity, will help to obtain a more accurate model.

\section{METHODOLOGY}

\subsection{Used data}

There are various sources for describing natural fracture networks. In this study, available information from 34 wells in the study area including core information, image logs, general logs, geophysical seismography and outcrops were used for the study. After the classification, the data needed for the modelling process were extracted as follows:

Well head (x. y. Kelly)

Well deviation (x. y. MD. z. inclination. Azimut)

Well $\log$

Chech shots to convert deep-time data

Fault data should be interpreted from the seismic section of the field faults.

Interpreted Horizontal Data

Fracture data (open and semi-open)

(Seismic data in the studied field due to the presence of a large part of the gypsum and salt layers in its formations, the diffraction phenomenon has occurred and the obtained section does not have the required quality)

\subsection{Methodology}

After adding the above data to the software, including: geometric conditions, faults of the region, type of formation and desired parameters, fracture modelling operations were performed in the Petrel software, and the DFN model was constructed. Then, by investigating the relationship between fracture data including fracture density and fracture direction with the existing logs, it was found that in the studied region, the pef $\log$ has a relation with the fracture density and the resistance logs has a relation with the direction of the fractures. This result can be further applied to modelling in wells that do not have an image log.

For this purpose, the following steps were taken to carry out the modelling:
The data was first transferred to a standard normal distribution.

The trend in data was investigated, due to the lack of specific trend; there was no need to delete the trend from the data.

The variogram was drawn in three main directions, major, minor, and vertical.

After plotting the variograms, the modelling of each fracturerelated log including resistance and PEF logs was performed using the geostatistical sequential Gaussian simulation method (SGS).

Then, the fracture-related parameters including fracture density and fracture aperture were conditioned to the simulated values of PEF and resistance logs using a sequential coexistence simulation (COSGS) method. In order to condition at any point in the estimate space $\mathrm{D}$, consider the true value of $Z 0(x)$ and the amount of kriging, such as $(\mathrm{x}) * \mathrm{kZ}$, in which case it is possible to write (1):

$$
Z 0(x)=\mathrm{Z} k *(\mathrm{x})+[Z 0(x)-\mathrm{Z} k *(\mathrm{x})]
$$

where: $[Z 0(x)-Z k *(\mathrm{x})]$ is a Kriging error. This error has an interesting feature that can be a conditional simulation key, which means that the following relation can be found between covariancs (2):

$\{Z k *(\mathrm{x})[Z(y)-Z *(y)]\}=0, \forall x, y \in D$

The truth of the above relation requires the following relationships (3):

$$
\begin{aligned}
& E\{\mathrm{Z} k * \quad(\mathrm{x}) \mathrm{Z} k * \quad(\mathrm{y})\}+E\{[\mathrm{Z}(x)-\mathrm{Z} k * \quad(\mathrm{x})][Z(y)-\mathrm{Z} k * \\
& (\mathrm{y})]\}=\mathrm{E}\{\mathrm{Z}(\mathrm{x}) \mathrm{Z}(\mathrm{y})\}=\mathrm{C}(\mathrm{x}-\mathrm{y})=\mathrm{C}(\mathrm{h}) \\
& (x)=\mathrm{Z} k *(\mathrm{x})+[Z s(x)-\mathrm{Z} s k *(\mathrm{x})]
\end{aligned}
$$

The estimation variance $Z s c \quad(x)$ simulated, which is considered as an estimate of $\mathrm{Z}(\mathrm{X})$, is derived from the following formula: (Journel \& Huijbregts, 1978) (4)

$E\{[Z s c(x)-Z(x)] 2\}=2 E\{[Z k *(x)-Z(x)] 2\}$

The variogram of Pef log was first drawn in three main directions in Figure 1, and using the plotted variogram parameters in Table 1, Structures of Pef variogram in study area was drawn in Figure 2. Due to the correlation between fracture intensity and Pef log, using the variogram parameters of Pef $\log$, the fracture intensity variogram parameters were estimated in Table 2 and its three-dimensional map was plotted in Figure 3.

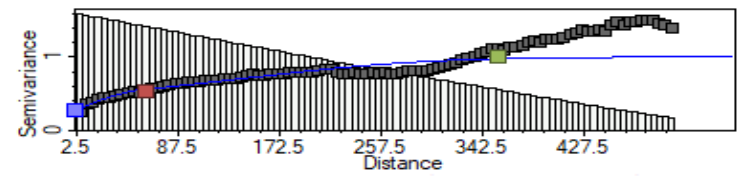

(a) 


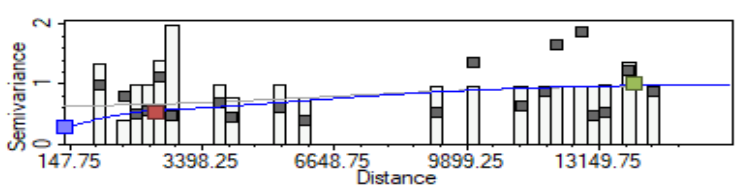

(b)

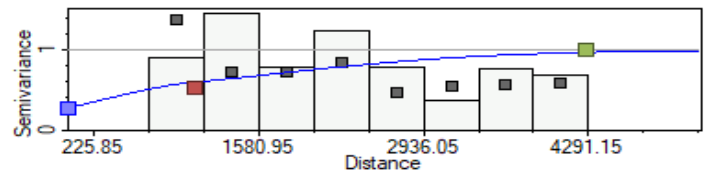

(c)

Figure 1. Variogram of pef log in vertical direction (a), major direction (b) and, minor direction (c)

Table 1. Variogram parameters in the pef log

\begin{tabular}{|c|c|c|c|c|c|c|c|c|c|}
\hline Direction & Azimuth & Dip & $\begin{array}{c}\text { Number } \\
\text { lags }\end{array}$ & $\begin{array}{c}\text { Lag } \\
\text { distance }\end{array}$ & $\begin{array}{l}\text { Search } \\
\text { radius }\end{array}$ & $\begin{array}{l}\text { Band } \\
\text { width }\end{array}$ & $\begin{array}{c}\text { Tolerance } \\
\text { angle }\end{array}$ & $\begin{array}{c}\text { Lag } \\
\text { tolerance }\end{array}$ & Thickness \\
\hline Vertical & NA & 90 & 100 & 5 & 500 & 50 & 45 & 50 & NA \\
\hline Major & 133.7 & 0 & 50 & 295.5 & 14775 & 816 & 24.7 & 50 & 0.001 \\
\hline Minor & 43.7 & 0 & 10 & 451.7 & 4517 & 6227.4 & 90 & 50 & 0.001 \\
\hline
\end{tabular}

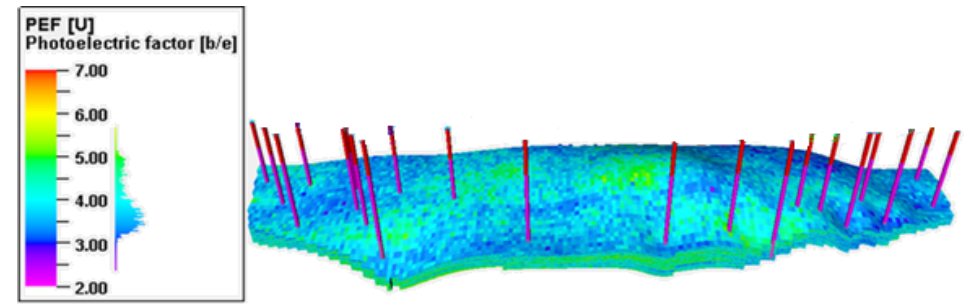

Figure 2. Structures of Pef variogram in study area

Table 2. Variogram parameters in the fracture intensity

\begin{tabular}{|cccccccccc}
\hline Direction & Azimuth & Dip & $\begin{array}{c}\text { Number } \\
\text { lags }\end{array}$ & $\begin{array}{c}\text { Lag } \\
\text { distance }\end{array}$ & $\begin{array}{c}\text { Search } \\
\text { radius }\end{array}$ & $\begin{array}{c}\text { Band } \\
\text { width }\end{array}$ & $\begin{array}{c}\text { Tolerance } \\
\text { angle }\end{array}$ \\
\hline Vertical & NA & 90 & 100 & 5 & 500 & 50 & 45 & 50 \\
Tajor & 133 & 0 & 20 & 977.2 & 19544 & 889 & 90 & 50 \\
Minor & 43 & 0 & 8 & 635.1 & 5080.8 & 6738.9 & 90 & 50 \\
\hline
\end{tabular}

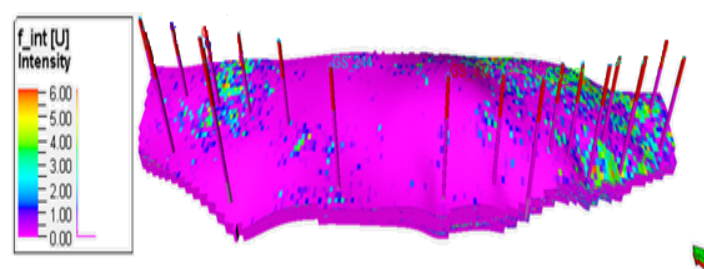

Figure 3. Structures of fracture intensity in study area

The variogram of resistivity log was drawn in three main directions in Figure 4, using the plotted variogram parameters in Table 3, Structures of resistivity variogram in study area was drawn in Figure 5. Due to the correlation between fracture aperture and resistivity log, using the variogram parameters of resisitivity $\log$, the fracture aperture variogram parameters were estimated in Table 4 and its three-dimensional map was plotted in Figure 6.

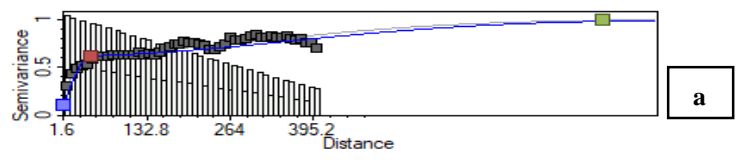



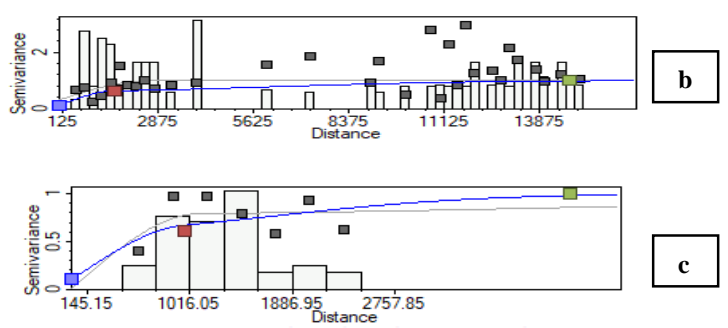

Figure 4. Variogram of resistivity log in vertical direction (a), major direction (b) and, minor direction (c)

Table 3. Variogram parameters in the resistivity log

\begin{tabular}{|c|c|c|c|c|c|c|c|c|c|}
\hline Direction & Azimuth & Dip & $\begin{array}{c}\text { Number } \\
\text { lags }\end{array}$ & $\begin{array}{c}\text { Lag } \\
\text { distance }\end{array}$ & $\begin{array}{l}\text { Search } \\
\text { radius }\end{array}$ & $\begin{array}{l}\text { Band } \\
\text { width }\end{array}$ & $\begin{array}{c}\text { Tolerance } \\
\text { angle }\end{array}$ & $\begin{array}{c}\text { Lag } \\
\text { tolerance }\end{array}$ & Thickness \\
\hline Vertical & NA & 90 & 50 & 8 & 400 & 54.2 & 84.7 & 50 & NA \\
\hline Major & 133 & 0 & 60 & 250 & 15000 & 731.9 & 90 & 50 & 0.001 \\
\hline Minor & 43 & 0 & 8 & 290.3 & 2322.4 & $\begin{array}{c}1777 . \\
7\end{array}$ & 90 & 50 & 0.001 \\
\hline
\end{tabular}

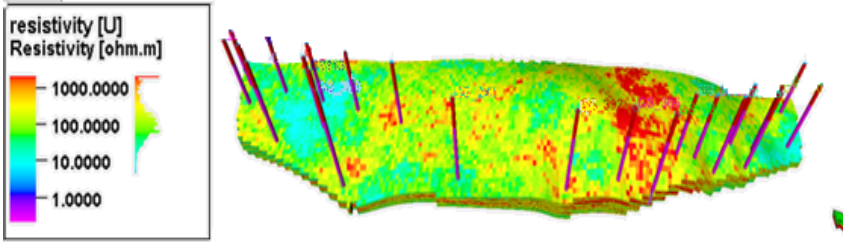

Figure 5. Structures of resistivity in study area Nugget effect: 0.3817

Table 4. Variogram parameters in the fracture aperture

\begin{tabular}{|c|c|c|c|c|c|c|c|c|c|}
\hline Direction & Azimuth & Dip & $\begin{array}{c}\text { Number } \\
\text { lags }\end{array}$ & $\begin{array}{c}\text { Lag } \\
\text { distance }\end{array}$ & $\begin{array}{l}\text { Search } \\
\text { radius }\end{array}$ & $\begin{array}{l}\text { Band } \\
\text { width }\end{array}$ & $\begin{array}{c}\text { Tolerance } \\
\text { angle }\end{array}$ & $\begin{array}{l}\text { Lag } \\
\text { tolerance }\end{array}$ & Thickness \\
\hline Vertical & NA & 90 & 50 & 12 & 600 & 50 & 45 & 50 & NA \\
\hline Major & 133 & 0 & 50 & 372.8 & 18640 & $\begin{array}{c}849 . \\
7\end{array}$ & 90 & 50 & 0.001 \\
\hline Minor & 43 & 0 & 8 & 1185.9 & $\begin{array}{c}9487 . \\
2\end{array}$ & $\begin{array}{c}6362 . \\
6\end{array}$ & 90 & 50 & 0.001 \\
\hline
\end{tabular}
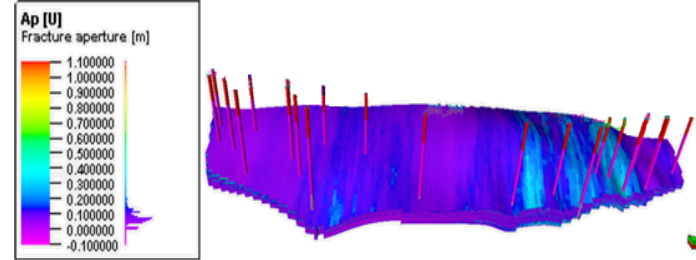

Figure 6. Structures of fracture aperture in study area

After estimating the fracture parameters (intensity and aperture) using the logs (Pef and resistivity) with the most relationship with them, it is time to build a conditional model for these results. Figure 7 shows the discreet fracture network made after conditioning.

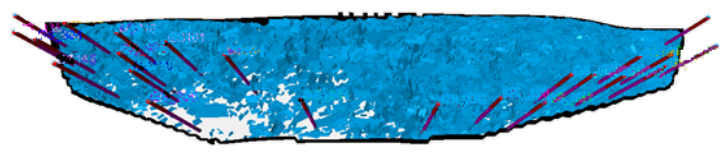

Figure 7. Final Discrete Fracture Network after conditioning

In order to study the accuracy of discrete fracture network made after conditioning, the correlation between the simulation results and the actual values in one of the wells whose fracture data was available and not used in the modelling process was investigated. The results are shown in Figure 8, 9, 10, 11.

In Figure 8, the relationship between the modelling fracture intensity and the actual fracture intensity before the conditioning is shown. In Figure 9, the relationship between 
the modelling fracture intensity and the actual fracture intensity after the conditioning is shown. Comparison of Figures 8 and 9 , shows that conditioning can increase the accuracy of the model by about $9 \%$.

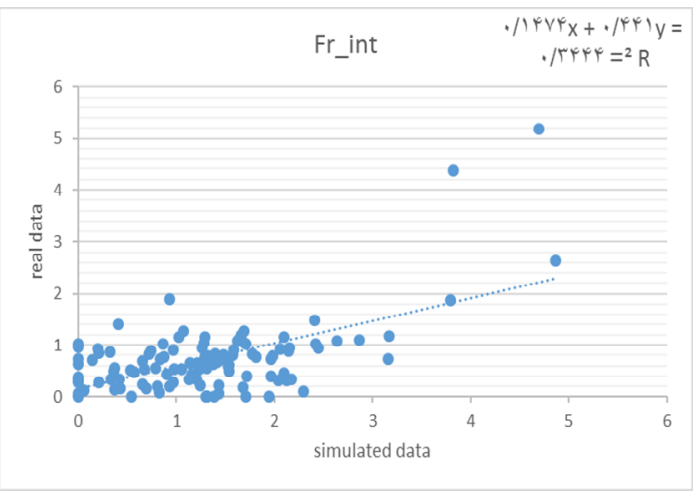

Corr $=0.5868$

Figure 8. Correlation between real and simulated fracture intensity data before conditioning

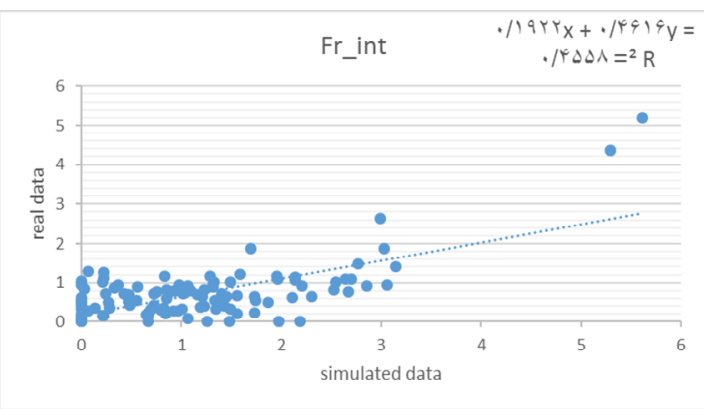

Corr $=0.6751$

Figure 9. Correlation between real and simulated fracture intensity data after conditioning

In Figure 10, the relationship between the modelling fracture aperture and the actual fracture aperture before the conditioning is shown. In Figure 11, the relationship between the modelling fracture aperture and the actual fracture aperture after the conditioning is shown. Comparison of Figures 10 and 11 , shows that conditioning can increase the accuracy of the model by about $5 \%$.

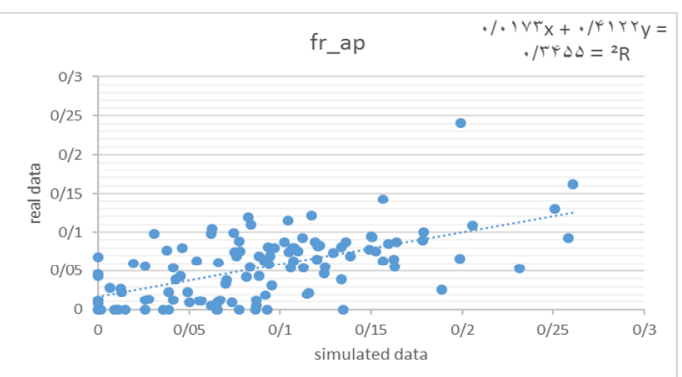

Corr $=0.5877$

Figure 10. Correlation between real and simulated fracture aperture data before conditioning

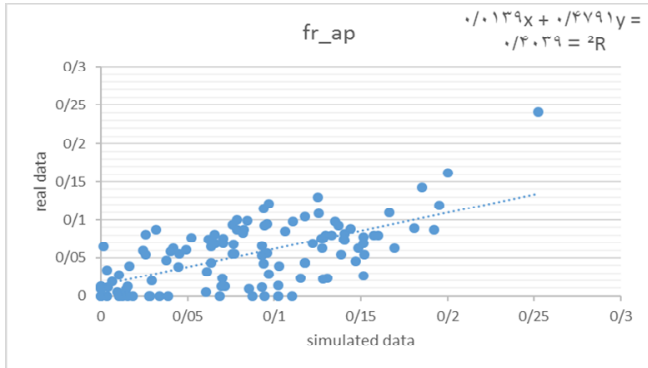

Corr $=0.6355$

Figure 11. Correlation between real and simulated fracture aperture data after conditioning

\section{CONCLUSION AND SUGGESTION}

Regarding the results of modelling, secondary variables can be used to improve the results of network fracture modelling in fields.

Increasing the scale of the values can add to the modelling accuracy. This will account for the fact that fractures within the formation continue. Also, using the proposed algorithm for modelling the direction of the fracture, a more accurate reproduction of the data observed on the image logs could be obtained. As it turned out in this study, using conditioning, the accuracy of the modelling in fracture density increases by about $9 \%$ and in the fracture opening increases by about $5 \%$.

This study only the beginning of a model for fracture network in fractured reservoirs and it is suggested that the results of this study with other methods of direct fracture identification including the use of core and indirect data including maps of mud lost, well test tools and other logs is merged to fracture network modelling and each of the named data is used as a secondary variable to improve the modelling.

Also, the use of multivariate geostatistical methods can be useful in evaluating the best modelling method for fracture network in future studies and it can be used to simulate the fracture network in a conditionally shaped reservoir rock as well. This shows that the approach used in this paper is promising and can be expanded to be used as a strong method in fracture modelling.

\section{References:}

Aghli, G. Soleimani, B. Moussavi-Harami, R. Mohammadian, R. 2016. Fractured zones detection using conventional petrophysical logs by differentiation method and its correlation with image logs, Journal of Petroleum Science and Engineering, 142, pp. 152-162. 
Anderson, J. Dverstop, B. (1987). "Conditional simulations of fluid flow in three-dimensional networks of discrete fractures", Water Resources Research, 23:1876-1886.

Baecher, G. Lanney, N. Einstein, H. (1977). "Statistical description of rock properties and sampling", Proceedings of the 18th US symposium on rock mechanics, Colorado School of Mines Press, Colorado.

Baecher, GB. (1983). "Statistical analysis of rock mass fracturing", Journal of the International Association for Mathematical Geology, 15(2):329-348.

Beydoun, ZR. (1998). "Arabian plate oil and gas: why so rich and so prolific?", Episodes-Newsmagazine of the International Union of Geological Sciences, 21:74-81.

Bourbiaux, B. Basquet, R. Cacas, M-C. Daniel, J-M. Sarda, S. (2002). "An integrated workflow to account for multi-scale fractures in reservoir simulation models: implementation and benefits", Society of Petroleum Engineers, 10th Abu DhabiInternational Petroleum Exhibition and Conference, Abu Dhabi, United Arab Emirates, Oct: 13-16.

Bourbiaux, B. Basquet, R. Daniel, J. Hu, L. Jenni, S. Lange, G. Rasolofosaon, P. 2005. Fractured reservoirs modelling: A review of the challenges and some recent solutions, First Break, 23 September.

Cacas, M. Daniel, J. Letouzey, J. 2001. Nested geological modelling of naturally fractured reservoirs, Petroleum Geoscience, 7(S), pp. S43-S52.

Chiles, J-P. Delfiner, P. 2009. Geostatistics: modelling spatial uncertainty, John Wiley \& Sons.

Clemo, T. 1994. Dual Permeability Modeling of Fractured Media, Caada University of British Columbia.

Dershowitz, W. Einstein, H. 1988. Characterizing rock joint geometry with joint system models, Rock Mechanics and Rock Engineering, 21, pp. 21-51.

Deutsch, CV. Journel, AG. 1998. GSLIB: Geostatistical Software Library and User's Guide, New York: Oxford University Press, $147 \mathrm{p}$.

Endo, HK. Long, JCS. Wilson, CK. Witherspoon, PA. 1984. A model for investigating mechanical transport in fractured media, Water Resources Research, 20, pp. 1390-1400.

Eskandari, S. Madani, H. Rasouli, V. Tokhmechi, B. 2008. Optimization of future drilling points in No. 3 Gol Gohar Iron mine using Fractal-Gaussian sequential simulation method, Iranian Journal of Mining Engineering, 5, pp. 11-19 (in Persian).

Gauthier, B. Zellou, A. Toublanc, A. Garcia, M. Daniel, J. 2000. Integrated fractured reservoir characterization", A case study in a North Africa fieldSociety of Petroleum Engineers.

Ghosh, A. Daemen, JJK. (1993). Fractal characteristics of rock discontinuities, Engineering Geology, 34, pp. 1-9.

Goovaerts, P. 1997. Geostatistics for Natural Resources Evaluation, Applied Geostatistics Series, New York, Oxford University Press.
Hugo, A. Pablo, L. Tomas, Z. Monte, A. Francisco, D. James, G. 2004. Dynamic Behavior of Discrete Fracture Network (DFN) Models, Proceedings of SPE InternationalPetroleum Conference in Mexico, Society of Petroleum Engineers, pp. 1-

Isaaks, EH. Srivastava, RM. 1989. An Introduction to Applied Geostatistics, New York, Oxford University Press Inc.

Journel, A. Zhang, T. 2006. The necessity of a multiple-point prior model, Mathematical Geology, 38, pp. 591-610.

Journel, AG. Huijbregts, CJ. 1978. Mining geostatistics, Academic press.

Kalkomey, CT. 1997. Potential risks when using seismic attributes as predictors of reservoir properties, The Leading Edge, 16, pp. 247-251.

Kim, J. Fessler, JA. 2004. Intensity-based image registration using robust correlation coefficients, Medical Imaging, IEEE Transactions on, 23, pp. 1430-1444.

Kuchuk, F. Biryukov, D. Fitzpatrick, T. 2014. Schlumberge, the International Petroleum Technology Conference held in Kuala Lumpur, Malaysia, pp. 10-12.

La Pointe, PR. 1988. A method to characterize fracture density and connectivity through fractal geometry, International Journal Rock Mechanic, 6, pp. 421-429.

Long, JCS. Remer, JS. Wilson, CR. Witherspoon, PA. 1982. Porous Media Equivalents for Networks of Discontinuous Fractures, Water Resources Research, 18, pp. 645-658.

Lyster, S. 2009. Simulation of Geologic Phenomena Using Multiple-Point Statistics in a Gibbs Sampler Algorithm, Edmonton. Alberta, Canada, University of Alberta.

Mäkel, G. 2007. The modelling of fractured reservoirs: Constraints and potential for fracture network geometry and hydraulics analysis, Geological Society, London, Special Publications, 292, pp. 375-403.

Maleki, M. Madani, N. 2016. Multivariate geostatistical analysis: an application to ore body evaluation, Iranian Journal of Earth Sciences, 8, pp. 173-184.

Mandelbrot, BB. 1983. The fractal geometry of nature, Revised and enlarged edition, New York, WH Freeman and Co.

Narr, W. Schechter, DS. Thompson, LB. 2006. Naturally Fractured Reservoir Characterization. Texas, Society of Petroleum Engineers, Richardson.

Nelson, R. 2001. Geologic analysis of naturally fractured reservoirs, Gulf Professional Publishing.

Pyrcz, MJ. Deutsch, CV. 2014. Geostatistical reservoir modelling, Oxford university press.

Renshaw, C. E. Pollard, DD. 1994. Numerical simulation of fracture set formation: a fracture mechanics model consistent with experimental observations, Journal of Geophysics, 99, pp. 9359-9372.

Robinson, PC. 1984. Connectivity, flow and transport in network models of fractured media, $\mathrm{PhD}$, Oxford University. 
Sahimi, M. 2011. Flow and transport in porous media and fractured rock: from classical methods to modern approaches, John Wiley \& Sons.

Schlumberger. 2003. Using borehole imagery to reveal key reservoir features, Reservoir Optimization Conference, Tehran, Iran.

Serra, O. 1989. Formation Microscanner Image Interpretation, Houston TX, Schlumberger Educational Services.

Shevlyakov, G. 1997. On robust estimation of a correlation coefficient, Journal of Mathematical Sciences, 83, pp. 434438.

Smith, L. Schwartz, FW. 1984. An analysis of fracture geometry on mass transport in fractured media, Water resource research, 20, pp. 1241-1252.

Srivastava, M. 2006. Field verification of a geostatistical method for simulating fracture network models, American Rock Mechanics Association.

Srivastava, RP. 2013. Fractals and wavelets in applied geophysics with some examples, Wavelets and Fractals in Earth System Sciences, CRC Press, pp. 155-176.

Stach, S. Cybo, J. Chmiela, J. 2001. Fracture surface-fractal or multifractal?, Mater Charact, 46, pp. 163-167.

Tingay, M. Heidbach, O. Davies, R. and Swarbrick, R. 2008. Triggering of the Lusi mud eruption: Earthquake versus drilling initiation, Geology. 36, pp. 639-642.

Wackernagel, H. 2003. Multivariate geostatistics, Springer Science \& Business Media.

Waldren, D. Corrigan, A. 1985. An engineering and geological review of the problems encountered in simulating naturally fractured reservoirs, Society of Petroleum Engineers. 